\title{
1 FABRIC CHARACTERISATION IN TRANSITIONAL SOILS
}

2 Todisco ${ }^{\mathrm{a}}$ M.C., Coop ${ }^{\mathrm{b}}$ M.R., Pereira ${ }^{\mathrm{c}}$ J.-M.

\section{ABSTRACT}

5 A "transitional" mode of soil behaviour implies that dense and loose samples do not converge 6 towards the same volumes within the strains and stresses applied by simple oedometer and 7 triaxial tests. As this behaviour involves soils with different gradings and mineralogies (e.g. 8 gap graded, well graded and/or mixed mineralogies), identifying the factors responsible is 9 difficult. Nevertheless, it has been previously speculated that strong forms of fabric that are difficult to break down as strains and stresses are applied, might be the common cause.

11 This paper aims at investigating some elements of fabric at the microscale of transitional soils. 12 A gap graded and two well graded mixtures with large amounts of non-plastic fines were investigated by oedometer and triaxial tests. As it would be difficult to identify experimentally many commonly used elements of fabric in these soils, e.g. the contact network, mercury intrusion porosimetry (MIP) was used as a first step to characterise the evolution of pore size distributions (PSDs) of dense and loose samples undergoing the same stress paths, using the PSDs as a proxy of fabric. Multi-directional bender element testing was performed to confirm the isotropy of the elastic stiffness, from which it might be inferred that the fabric is also isotropic. Statistical parameters of the PSDs were calculated, the changes of which were related to the evolution of macroscale void ratios.

The robust fabrics causing lack of convergence were characterised by a complex evolution of the PSDs, the initial differences of which could not be erased during conventional testing. This work also provided a simple method to examine the fabric of particularly well graded or gap graded materials, for which other techniques, such as CT or SEM, could not reveal the multiscale nature of the fabric.

KEY-WORDS: fabric, MIP, statistical parameters, transitional soils

\section{Authors Affiliations}

${ }^{a}$ Corresponding Author, Coffey Geotechnics, Atlantic House, Atlas Business Park,

29 Manchester UK formerly City University of Hong Kong, cristina.todisco@tetratech.com

$30 \quad{ }^{\mathrm{b}}$ University College London, Chadwick Building, Gower Street, London 
1 c Laboratoire Navier, UMR 8205, École des Ponts ParisTech, IFSTTAR, CNRS, UPE,

2 Champs-sur-Marne, France

\section{NOMENCLATURE}

$4 \quad \mathrm{G} \quad$ elastic shear modulus

$5 \mathrm{G}_{\mathrm{hh}}$ shear modulus calculated from horizontally propagated, horizontally polarised shear 6 waves

$7 \mathrm{G}_{\mathrm{hv}}$ shear modulus calculated from horizontally propagated, vertically polarised shear 8 waves

$9 \mathrm{G}_{\mathrm{vh}}$ shear modulus calculated from vertically propagated, horizontally polarised shear 10 waves

11 LBS Leighton Buzzard sand

12 LMS Crushed limestone

13 PSD pore size distribution

14 SPF sand plastic fines (75\% sand-25\% kaolin)

$15 \gamma \quad$ skewness of PSD

$16 \kappa \quad$ kurtosis of PSD

$17 \mu \quad$ mean of PSD

$18 \sigma \quad$ standard deviation of PSD

19 


\section{INTRODUCTION}

2 A range of soils has now been observed to have a so called "transitional" mode of behaviour,

3 for which convergence of loose and dense samples towards unique volumes is not seen either

4 in compression or shearing within the range of strains that may be applied by simple oedometer

5 or triaxial tests. The factors responsible for this have not clearly been identified but it has been

6 speculated that it results from strong fabrics at the microscale that are difficult to break down

7 [1]. However, identifying those elements of fabric responsible has proven elusive, mainly

8 because of the difficulty of defining the fabrics of soils composed of a wide range of particle

9 sizes and/or different mineralogies and that may have undergone complex geological processes

10 (e.g. $[2,3])$.

11 Some natural soils characterised by strong forms of fabrics may show analogous behaviour of

12 transitional soils. These robust fabrics can be observed at different scales and in different forms

13 and due to this variability they are often classified as being heterogeneous. Heterogeneity might

14 be found in particle and pore arrangements and topology and in force chain transmission,

15 although the latter has been less investigated experimentally. For example, natural alluvial clayey soils (e.g. [4, 5]) often have heterogeneous fabrics at the mesoscale with thin depositional layers of fine and coarse soils and have been found to have compression behaviour that is not convergent with the compression lines of their remoulded soils. Other clays may have silt-sized aggregates formed by clays minerals and are heterogeneous at the microscale (e.g. $[6,7])$, with different behaviours according to the degree of aggregate destructuration applied. Also DEM simulations on fractally graded sand mixtures showed transitional mode of behaviour when subjected to conventional laboratory compressive stress levels (<8MPa) [8]. In this case robust fabrics were observed by analysing the force chain transmission. Strong force chains were carried by big particles, with the large voids compressed, while the small particles were either weakly loaded by the adjacent big particles or filling voids without transmitting any force, so that the small voids were little affected.

27 Based on these observations and the fact that their soils had isotropic strains, Shipton and Coop [9] speculated that the fabric that was responsible for transitional behaviour might have a heterogeneous rather than anisotropic nature at the microscale, although the representative element volume for that micro fabric could not be defined. It is possible that the former is a more robust characteristic, since the latter may often be erased or at least modified as the test proceeds. The effects of fabric anisotropy on soil behaviour have been extensively studied at 
1 the macro and mesoscales $[10,11,12]$, but there is very much less research on the effects of

2 fabric heterogeneity at the microscale.

3 X-ray CT scanning and scanning electron microscopy, SEM, have both been used extensively to characterise soil structure and relate changes to the macromechanical behaviour (e.g. [13, $14,15,16,17])$. But for transitional soils, which are often gap graded or very well graded, a clear detection of the fabric elements responsible is difficult to achieve due to the difficulty of examining the fabrics at the scales of the smaller and larger particles simultaneously (see Appendix Figure A1 for an example). Nocilla et al. [18] and Shipton and Coop [9] both tried SEM in unsuccessful attempts to identify the fabric responsible for the transitional behaviour that they observed. Mercury intrusion porosimetry MIP overcomes this shortcoming, detecting pore sizes from a few $\mathrm{nm}$ to a few hundreds of $\mu \mathrm{m}$, although it is limited to characterising the soil structure only in terms of pore size distribution (PSD).

This paper aims at investigating the fabrics of transitional soils by means of MIP, examining the PSD and its evolution during conventional laboratory testing. In MIP tests, the volume of voids is measured over the volume of sub-samples of about $0.5-1 \mathrm{~cm}^{3}$. It was found that the Representative Elementary Volume REV for an unsaturated fine sand was about 30-45 times larger than the particle size, equal to $10-15 \mathrm{~mm}$ [19]. The REV for the materials presented in this work was not investigated but given their grain size distributions and the reasonable repeatability of most of the MIP results, it was assumed that the size of the MIP samples was large enough to capture representative PSDs of the whole samples. The PSDs were analysed by statistical parameters that were related to the macromechanical behaviour of the soils. It should be emphasised that MIP can only give information about one aspect of soil fabric, i.e. the pore size distribution, and gives no information about the precise nature of particle and void distributions and orientations that create the fabric. Since MIP cannot address fabric anisotropy, this has been inferred indirectly by means of multi-directional bender elements.

\section{MATERIALS AND METHODS}

The effects of the fabric have been studied for three mixtures, of which the mechanical behaviours were described in detail in Todisco and Coop [20] and Shipton and Coop [21, 9], and additional tests were carried out specifically to examine the fabric. The SPF (sand with plastic fines) is a gap graded mixture made of 75\% Thames Valley sand [22] and 25\% kaolin. 
1 Its mechanical behaviour revealed apparently parallel normal compression lines (NCLs) and critical state lines (CSLs) in the state plane for different initial void ratios [21,9]. The LBS and LMS were very well graded samples of Leighton Buzzard quartz sand and a crushed limestone from China. In both cases the maximum particle size was $600 \mu \mathrm{m}$, and within the sand fraction a fractal grading of 2.57 was used $[23,20]$. Since it was not possible to control the grading within the fines fraction also to be fractal, the gradings were completed with $40 \%$ of crushed quartz silt or crushed limestone silt. The grain size distributions of the mixtures are shown in

8 Fig. 1. The SPF samples were created by the moist-tamping method, varying the initial water content and number of layers as indicated in Shipton and Coop [9] to change the initial void ratio. The samples of LBS and LMS were created by the dry compaction method which follows the procedure of the under-compaction method [24] but using dry reconstituted soils.

The one-dimensional tests on SPF were performed in conventional oedometers, using a $50 \mathrm{~mm}$ diameter ring to reach a vertical stress level of about 8MPa. Smaller 20 and 30mm rings were used to reach vertical stresses of around $20-50 \mathrm{MPa}$, but these had a floating ring design to minimise the side friction. The triaxial tests were carried out in typical stress path type apparatuses. The samples were saturated by first circulating $\mathrm{CO}_{2}$, then flushing with de-aired water and finally by applying back pressures of at least $200 \mathrm{kPa}$, obtaining $\mathrm{B}$ values of 0.96 0.98. After connecting a suction cup to link the axial loading system rigidly to the sample [25], isotropic compression to different stress levels was followed by drained shearing under axial strain control, typically using a gradual increasing rate from $0.05 \% / \mathrm{h}$ in the small strain region $(<0.1 \%$ axial strain) to $0.4 \% / \mathrm{h}$ at large strains. This was a pragmatic choice to complete the tests in a relatively short time, while ensuring complete drainage, although very small rate effects in the stress-strain curves were observed. However, the samples were retrieved at the end of the tests after reaching the critical state. It has been shown that rate effects become negligible on both stress and state planes as axial strains increase (e.g. [26, 27]). Full details of the tests are given in Tables 1 and 2.

\section{Multi-directional bender element testing}

A Bishop and Wesley [28] triaxial apparatus was fitted with T-configuration lateral bender elements [29] able to measure the stiffnesses $G_{h v}$ and $G_{h h}$. These were inserted through the membrane using a specially designed mould, described in detail in Todisco [30]. The pedestal and top platen also housed axially orientated bender elements to measure $G_{\mathrm{vh}}$. The data from these were consistent with $\mathrm{G}_{\mathrm{hv}}$ and $\mathrm{G}_{\mathrm{hh}}$, but since the vertical bender elements have different 
1 boundary conditions to the lateral, data from them tended to increase the scatter and so for this

2 reason they have not been presented in the analysis. The shear wave velocities were calculated

3 using the first arrival time [31] ensuring a consistent choice over a range of frequencies from

48 to $20 \mathrm{kHz}$.

Mercury intrusion porosimetry (MIP) tests

6 The MIP tests were carried out using an AutoPore IV 9500. Applying Eq. 1 [32] it was possible

7 to obtain the pore diameter intruded by the pressurised mercury

$9 p=-\frac{n \sigma_{H g} \cos \theta}{d}$

11 where $\mathrm{p}$ is the absolute pressure applied to the mercury, $\mathrm{n}$ is a coefficient accounting for the 12 pore shape, a value equal to 4 (corresponding to a cylinder) being adopted in this study, $\sigma_{\mathrm{Hg}}$ is 13 the surface tension of the mercury equal to $0.484 \mathrm{~N} / \mathrm{m}$ at $25^{\circ} \mathrm{C}, \theta$ is the contact angle between 14 the pore contour and the mercury and in this study is assumed equal to $130^{\circ}$ and $\mathrm{d}$ is the pore throat diameter. Different contact angles were reported in the literature with values ranging from $130^{\circ}[33]$ to $160^{\circ}[34,35]$. The SPF samples were freeze-dried after being carefully waxcoated at the end of the tests, while the LBS and LMS samples were oven-dried. The freezedrying technique was used for the sand-clay mixture SPF to avoid bulk shrinkage and changes in pore size distribution $[34,13]$, while it was not necessary for the LBS and LMS because they were non-plastic.

In each case the MIP samples were carefully trimmed to a size roughly equal to $1 \mathrm{~cm}^{3}$, but optimised depending on the porosity of each sample to obtain the best resolution from the apparatus. The oedometer and triaxial sub-samples were retrieved after unloading. The trimming of the SPF was relatively straightforward, but the trimming and handling of the sand samples required extreme care and neither sand could be sampled and tested in its initial state, the samples either collapsing during trimming or during initial immersion in the mercury. For the final states, some, but not all tests were successful. The successful tests resulted perhaps because their very well graded nature ensured that they just had sufficient particle interlock after loading to allow the test to be done successfully, or perhaps because there was a tiny amount of bonding created by loading, especially in the LMS. The slight cohesion in the 
1 samples could not have resulted from suction as the MIP test is carried out under a very high vacuum.

3 The pore size distributions, PSDs, are shown with the $\mathrm{x}$-axis on a logarithmic scale, as often 4 adopted for data spreading over many orders of magnitude. PSDs were analysed in terms of statistical parameters that offered a valuable tool to describe the shape of a probability density function. Sedimentologists use this approach to describe particle size distributions by reading selected percentiles of the cumulative curves (e.g. [36]). Here, the method of the scaled moments [37] was preferred as it can be applied to the majority of the curve shapes (i.e. nonnormal distributions). The statistical parameters of the PSDs were the mean $(\mu)$, standard deviation $(\sigma)$, skewness $(\gamma)$ and kurtosis $(\kappa)$. An i-th moment is scaled when it is divided by the standard deviation to the $\mathrm{i}$-th exponent. The first scaled moment is 0 because the moment with exponent 1 around the mean is 0 , the second is 1 because the moment with exponent 2 around the mean is the variance $\sigma^{2}$, the third and the fourth scaled moments are skewness and kurtosis. The statistical parameters were calculated manually using the discrete values of the functions obtaining from the MIP tests. Equations 2-6 explain the procedure in detail. At each discrete value of $\mathrm{x}_{\mathrm{i}}$ that is the log of pore diameter, the $\mathrm{i}$-th area under the probability function $\Delta \mathrm{A}_{\mathrm{i}}$ is equal to:

where $f\left(x_{i}\right)$ is the $i$-th value of the density function, also called incremental pore volume in the following figures. The mean was calculated as

$27 \quad \sigma=\sqrt{\frac{\sum_{i=1}^{n} \Delta A_{i}\left(\Delta x_{i}-\mu\right)^{2}}{\sum_{i=1}^{n} \Delta A_{i}}}$ 
1 where $\Delta \mathrm{x}_{\mathrm{i}}-\mu$ is the distance of the $\mathrm{i}$-th log pore diameter interval from the mean. The values 2 shown in the Results section are the inverse of the logarithmic values obtained by Eq.4. The 3 skewness $\gamma$ and the kurtosis $\kappa$ were calculated as:

$5 \quad \gamma=\frac{\sum_{i=1}^{n} \Delta A_{i}\left(\Delta x_{i}-\mu\right)^{3} / \sum_{i=1}^{n} \Delta A_{i}}{\sigma^{3}}$

$7 \quad \kappa=\frac{\sum_{i=1}^{n} \Delta A_{i}\left(\Delta x_{i}-\mu\right)^{4} / \sum_{i=1}^{n} \Delta A_{i}}{\sigma^{4}}$

9 The statistical parameters may be compared to those of a normal distribution that has a $\gamma$ of 0 10 and $\kappa$ of 3 . The value of $\gamma$ locates the centre of mass of the distribution, a negative value defining 11 a left-skewed distribution with the centre of mass to the left of the mean and longer tail towards 12 the right. The value of $\kappa$ defines the sharpness of the peak and the thickness of the tails; if it is 13 greater than 3 then the peak is sharper and tails longer and thicker than for a normal distribution. 14 These statistical parameters for the PSDs were plotted against the final void ratios of the tests to try to relate the macromechanical behaviour to the fabric.

\section{RESULTS}

Changes to void ratio in compression and shear

Figure 2 shows the mechanical behaviour of selected SPF, LBS and LMS samples that were subjected to MIP and bender elements (BE) testing. These were part of a more extensive experimental campaign, which investigated the transitional behaviour of these mixtures in compression and shearing [20] although additional tests have been carried out in this investigation of fabric. The sample names help to indicate the initial void ratio and the maximum stress level. For example, LI and DI indicate loose and dense samples of SPF in their "initial state" which was one of one-dimensional compression to about $50 \mathrm{kPa}$, so that the samples were firm enough to be handled and trimmed; LF and DF were different samples with initial void ratios similar to LI and DI but compressed to $8 \mathrm{MPa}$ and then retrieved after unloading to $50 \mathrm{kPa}$ for the MIP tests. 
1 Values of mean effective stress $\mathrm{p}^{\prime}$ were plotted for the oedometer tests on SPF and LMS by assuming $\mathrm{k}_{0}=1-\sin \varphi^{\prime}$ [38], where $\mathrm{k}_{0}$ is the coefficient of earth pressure at rest equal to $\sigma^{\prime}{ }_{3} / \sigma_{1}^{\prime}$ for zero lateral strain and $\varphi^{\prime}$ is the angle of shearing resistance. In standard oedometer tests only the vertical stress $\sigma_{1}^{\prime}$ is known, calculated from the applied load, while the horizontal stress $\sigma_{3}^{\prime}$ is obtained by multiplying $\sigma_{1}^{\prime}$ by $\mathrm{k}_{0}$. The mean effective stress $\mathrm{p}^{\prime}$ is the first stress invariant equal to $\frac{\sigma \alpha_{1}+2 \sigma_{3}}{3}$, where $\sigma_{1}^{\prime}$ and $\sigma_{3}^{\prime}\left(=\sigma_{2}^{\prime}\right.$ i.e. axisymmetric conditions $)$ are the major and minor principal effective stresses. For the LBS two samples were tested using lubricated end platens in the triaxial, but as discussed by Todisco and Coop [20] this did not affect the data significantly in comparison to the much larger differences of void ratio between different samples. The samples tested using bender elements (BE) and MIP are indicated in the graphs.

\section{Multi-directional bender element tests}

13 First, the characterisation focused on the fabric anisotropy and the data from the multidirectional bender element tests during isotropic compression are given in Fig. 3. These indicated that the elastic stiffnesses were isotropic, the $G_{h v}$ and $G_{h h}$ values being very similar, from which it is inferred that the fabrics were also isotropic. The BE tests on SPF confirm the isotropy that was suggested by Shipton and Coop [9] from an examination of the axial and volumetric strain increments during isotropic compression. A loose (LBS16) and dense (LBS17) sample of LBS shows little difference in the stiffnesses. From small strain probes Shipton and Coop [9] had tentatively reached a similar conclusion for the SPF, but their data were rather more scattered.

MIP results

The density distribution curves for the tests on SPF are given in Figure 4. The samples in their initial states (post-50kPa-compression), LI and DI show that they have significantly different PSDs, the loose (LI) having larger pores and a broader peak than the dense. The broad peak in fact consists of a slight double peak. The small trough at about $6 \mu \mathrm{m}$ may be disregarded as it occurs at the transition from the low to the high pressure analysis port. Compression moved the PSDs towards the region of smaller pores, as expected but it did not influence the distributions of pores smaller than $0.2 \mu \mathrm{m}$. The broad peak of loose sample LI was reduced in 
1 the final state (LF) as the individual peak for the larger pores reduced while that for the smaller 2 pores increased. For the final dense sample (DF) there is a very much increased difference between the two initial peaks (DI), with the peak for the larger pores reduced very much more than for the loose samples. The initial dense distribution (DI) and final loose (LF) are actually quite similar, and on Fig. 2 they have quite similar void ratios. The final PSDs at the same vertical stress of about $8 \mathrm{MPa}$ remain significantly different, corresponding to their different void ratios, the denser sample having far fewer large voids. As the PSD is a fabric element, it could be concluded that these fabrics, as characterised here solely by the pore distributions, are robust and cannot be erased completely by compression. None of the PSDs showed the very marked bimodality found by Juang and Holtz [39], who tested a similar mixture of $30 \%$ kaolin70\% Ottawa sand. Perhaps, the compaction method of Juang and Holtz [39] generated a different fabric to the moist tamping method used here.

Figure $4 \mathrm{~b}$ shows the PSDs of final samples of SPF sheared drained in the triaxial at $300 \mathrm{kPa}$. It is possible that the data might be affected by experimental uncertainties, exacerbated by the small number of tests. However preliminary conclusions can be drawn, which seem consistent with the mechanical behaviour, although a more exhaustive validation is needed from future research. The distributions are quite different to those for the oedometer tests, which might be because of the different strains applied during one-dimensional compression and shearing and to the different volumetric behaviours of the loose and dense samples; SPF1 was contractive while SPF2 was dilative. Nevertheless, the distributions for the loose (SPF1) and dense samples (SPF2) are again quite different, which may justify their differences in void ratio in Fig. 2a. The fabrics, in terms of PSDs, have again not converged even after shearing to about $30 \%$ axial strain.

To check whether fabric can be related to convergence, two control tests were carried out, testing dense and loose kaolin samples in the oedometer. These reached a unique NCL at about $100 \mathrm{kPa}$ (Fig. 5a). The samples were prepared as slurries at different initial water contents in order to obtain different initial void ratios. In Fig. 5b, the PSDs soon after compression have peaks at almost the same pore diameter (about $0.2 \mu \mathrm{m}$ ) and are very similar over the full range of pore sizes.

Because of the difficulties in trimming and carrying out the tests on the sands, many of the MIP tests were not successful. A selection of those that were comparable is shown in Fig. 6 where 
1 the stress levels and final void ratios have been indicated for each sample. All the PSDs can be 2 defined as unimodal independently of the loading type. Unfortunately, the unimodal shapes 3 highlight that the differences for the sands are much less clear than for SPF only showing that 4 dense samples have smaller modes (most frequent value of pore diameter) and extra smaller 5 pores than the loose ones, the PSDs being slightly shifted to the left. For the LMS, the two 6 oedometers were loaded to the same vertical stress of about 50MPa and the compression paths 7 of the loose (LMS-OED1) and dense (LMS-OED2) samples were tending to converge slowly 8 (Fig. 2c) but there were still significant differences in both void ratio and PSDs. The PSDs of 9 the oedometers resemble a normal distribution, except for some lack of symmetry of the tails due to the presence of large pores.

11 The PSDs of the mixtures, especially the SPF ones, show that compression to stress levels smaller than $8 \mathrm{MPa}$ affects only pore between 0.2 and $10 \mu \mathrm{m}$, leaving unchanged the distributions of the smaller ones. Although MIP tests cannot investigate force chain transmission, it might be inferred that transitional behaviour in the mixtures arises because forces are not carried homogeneously by all the particles [8]. This justifies the changes of PSDs only in specific regions of pores.

Overall, the results of MIP tests tend to confirm that different PSDs are associated with different void ratios for the type of transitional soils presented in this work, while MIP tests on convergent samples of kaolin reached a unique PSD.

\section{Statistical analysis of the PSDs}

In Fig. 7, the mean values (solid markers) of the PSDs of the oedometers and triaxials on SPF are rather different but both decrease as void ratio decreases. It seems that for the oedometers, where there are more data, the mean is fairly well related to void ratio, no matter whether it is at the start or end of the test. The direct comparison between the final values of LF and DF, shows that the final mean does not converge to a unique value. In contrast the standard deviation of the oedometers does not vary significantly, and is similar for the initial and final values and for dense and loose samples. However, that of the triaxials decreases with decreasing void ratio. The standard deviation is larger than the mean probably because the pore size covers several orders of magnitude. The skewness $\gamma$ and kurtosis $\kappa$ of the oedometer and triaxial samples are more similar, but they are both slightly lower for the triaxials. With some 
1 data scatter, it again seems to be the case that for the oedometers the skewness and kurtosis are 2 related to void ratio but both increase with decreasing void ratio, so again the final dense and 3 loose samples have distinctly different values. In summary, after compression and shearing the PSDs of the SPF evolve into those with smaller pores on average, longer and thicker tails in the region of small pores $>0.2 \mu \mathrm{m}$ with a sharper peak (increasing kurtosis, $\kappa$ ) and a centre of mass located in the region of large pores (right skewed, increasing positive $\gamma$ ).

Figure 8 shows the statistical parameters for LBS and LMS. The differences are not large, mostly because the sample void ratio differences were also much smaller than for the SPF and the data are few. The mean of both sands decreases as void ratio decreases, as might be expected, but much less than for the SPF. This might be because the sand-clay mixture is more compressible overall than the well graded sands. In this case, the standard deviations increase slightly and the skewness of LBS samples increases as void ratio reduces, like the SPF but here $\kappa$ remains nearly constant. The constant value of $\kappa$ of LBS indicates that the sharpness of the peaks and the thickness of the tails are not significantly different between the dense and loose final samples.

Both the $\gamma$ and $\kappa$ of LMS decrease significantly in contrast to what was seen in the other soils. The mean and skewness do not change as much as observed in the SPF samples, even allowing for the smaller differences on void ratio.

Table 3 summarises the statistical parameters of comparable samples of the various soils, each comparison with a similar type of test and stress level. The median and the diameter ratio $\mathrm{d}_{60} / \mathrm{d}_{10}$ considering the pore sizes at the 60 and $10 \%$ percentiles of the cumulative distributions have been added as a quantification of the symmetry and uniformity of the data. The ratio $\mathrm{d}_{60} / \mathrm{d}_{10}$ is similar the coefficient of uniformity adopted for the characterization of grain size distributions. If it is less than 4, the soil is defined as uniformly graded. Generally, the mean values for the gap graded SPF vary much more between loose and dense samples than those of the sands, but this is expected since the SPF void ratios cover a wider range, both at the start and end of tests. The median decreases with decreasing void ratio and shows generally smaller values than the mean. This indicates that the distributions are not symmetric but shifted toward the region of large pores, i.e. positive skewness values. The standard deviation of the SPF is larger than that of the sands, so that the SPF has more variability around the mean diameter than the well graded sands. The skewness is always positive and does not vary greatly between the well graded sands and the sand with plastic fines, the values ranging between 0.63 and 1.88 . The kurtosis 
1 values are generally larger than 3, with the exception of test SPF1. This means that all the PSDs 2 have sharper peaks and thicker tails than a normal distribution. The ratio $\mathrm{d}_{60} / \mathrm{d}_{10}$ is larger than 34 for SPF and LBS samples indicating that the pores are poorly sorted while LMS samples show more uniform distributions. As the samples become denser the uniformity of the distributions increases revealing that the compression and/or shearing tend to reduce the large

6 initial differences in pore size.

\section{CONCLUSIONS}

9 The fabrics of three soils that might be described as "transitional" were characterised in terms 10 of their pore size distributions, which were characterised as heterogeneous because covering 11 large range of pore sizes. The similarities between stiffnesses, $\mathrm{G}_{\mathrm{hv}}$ and $\mathrm{G}_{\mathrm{hh}}$, measured by multidirectional bender elements, suggested that in each case the fabrics are isotropic. The stiffnesses of the LBS were found to be poorly related to the densities of the samples and mostly dependent on the stresses applied. These results emphasise that the transitional mode of behaviour found for the three mixtures, or lack of convergence of void ratios in simple laboratory tests, must be a real soil behaviour, and is not related to any inherent anisotropy that might be generated during sample preparation.

MIP testing proved to be a good technique to characterise transitional soil behaviour in terms of micro fabric changes (PSDs changes). The MIP tests on SPF showed that the robust initial PSDs of the dense and loose samples were distinctly different and not erased during compression and/or shearing. Also pores between 0.2 and $10 \mu \mathrm{m}$ experienced the largest changes during compression, while the smaller ones remained almost unaffected. The MIP tests on the LBS and LMS were very much more difficult to conduct, with many failed tests and more scattered data. Also the narrower range of void ratios achieved, the unimodal nature of the PSDs and smaller changes of PSD with void ratio in the case of LBS, meant that they were more difficult to characterise than the SPF. Nevertheless, the data allow some significant conclusions still to be drawn. The loose and dense LBS samples sheared at the same isotropic pressure and also the oedometer tests on LMS showed different final PSDs that corresponded to their different final void ratios, the denser samples having smaller pores than the loose ones, as expected, but also with other changes to the shapes of the distributions. Two control oedometer tests on samples of kaolin, confirmed that a convergent void ratio can correspond to a convergent PSD. This might indicate that void ratios and pore distributions are directly 
1 linked for these soils: different void ratios correspond to different PSDs and similar void ratios

2 have similar PSDs. However, in other cases it is not excluded that soils might have similar void ratios but different PSDs (e.g. [39]).

4 Statistical parameters were applied to the PSDs for the first time. The quantitative parameters were linked to the state of the soils, providing a description of the evolution of the PSDs during compression and/or shearing. The mean and median of all the mixtures decreased as the samples became denser, while the trends of standard deviation, skewness, kurtosis and $\mathrm{d}_{60} / \mathrm{d}_{10}$ depended on the type of soil and test. This work offers a new insight on the fabric of transitional soils. The robust fabrics causing lack of convergence were isotropic and characterised by a complex evolution of the pore size distributions, the initial differences of which could not be erased during conventional testing. It also provided a simple method to examine the fabric of particularly well graded or gap graded materials, for which other techniques, such as CT or SEM could not reveal the multi-scale nature of the fabric. The statistical analysis of the PSDs and their relationship to soil states might be adopted more widely for other materials. Furthermore, such analyses open new perspectives on modelling the behaviour of soils based on the knowledge of their PSD and its evolution with state parameters. For instance, the present work lets envisage an extension to soils of the work by Arson and Pereira [40] and Pereira and Arson [41], who related the hydro-mechanical behaviour of damaged rocks to their PSD.

\section{ACKNOWLEDGEMENTS}

The work described in this paper was fully supported by a grant from the Research Grants Council of the Hong Kong Special Administrative Region, China (project no. CityU 112813). The authors are grateful to Prof. Pierre Delage for his valuable comments on MIP data. The technician Mr. Xavier Boulay and Baptiste Chabot are acknowledged for their technical support in conducting the MIP tests. Also, we would like to thank the reviewers for their constructive remarks which helped to improve the quality of the paper.

The authors certify that they have NO affiliations with or involvement in any organization or entity with any financial or non-financial interest (such as personal or professional relationships, affiliations, knowledge or beliefs) in the subject matter or materials discussed in this manuscript. 


\section{REFERENCES}

2 [1] Coop, M. R.: Limitations of a Critical State framework applied to the behaviour of natural

3 and "transitional" soils. Proc. of 6th International Symposium on Deformation Characteristics

4 of Geomaterials, IS-Buenos Aires, 115-155 (2015)

5 [2] Ferreira, P. M., Bica, A. V. D.: Problems in identifying the effects of structure and critical

6 state in a soil with a transitional behaviour. Géotechnique 56 (7), 445-454 (2006)

7 [3] Altuhafi, F. N., Baudet, B. A., Sammonds, P.: The mechanics of subglacial sediment: an 8 example of new "transitional behaviour". Can. Geotech. J. 47 (7), 775-790 (2010)

9 [4] Coop, M. R., Cotecchia, F.: The compression of sediments at the archaeological site of Sibari. Proc. of 11th ECSMFE-Copenhagen, Vol. 1, 19-26 (1995)

11 [5] Cotecchia, F., Chandler, R. J.: One-dimensional compression of a natural clay: structural 12 changes and mechanical effects. Proc. of the Second International Symposium on Hard Soils13 Soft Rocks, Naples, 103-114 (1998)

14 [6] Fearon, R. E., Coop, M. R.: Reconstitution: what makes an appropriate reference material? 15 Géotechnique 50 (4), 471-477 (2000)

16 [7] Atkinson, J. H., Fookes, P. G., Miglio, B. F., Pettifer, G. S.: Destructuring and 17 disaggregation of Mercia Mudstone during full-face tunnelling. Quart. J. Eng. Geol. \& 18 Hydrogeol. 36 (4), 293-303 (2003)

19 [8] Minh, N. H. and Cheng, Y. P.: A DEM investigation of the effect of particle-size 20 distribution on one-dimensional compression. Géotechnique 63 (1), 44-53 (2013)

21 [9] Shipton, B. and Coop, M. R.: Transitional behaviour in sands with plastic and non-plastic 22 fines. Soils and Foundations 55 (1), 1-16 (2015)

23 [10] Oda, M.: Initial fabrics and their relations to mechanical properties of granular material. 24 Soils and Foundations 12 (1), 17-36 (1972)

25 [11] Kuwano, R., Jardine, R. J.: On the applicability of cross-anisotropic elasticity to granular 26 materials at very small strains. Géotechnique 52 (10), 727-749 (2002) 
1 [12] Yang, Z. X., Li, X. S. Yang, J.: Undrained anisotropy and rotational shear in granular soil.

2 Géotechnique 57(4), 371-384 (2007)

3 [13] Delage, P., Lefebvre, G.: Study on the structure of a sensitive Champlain clay and of its 4 evolution during consolidation. Can. Geotech. J. 21 (1), 21-35 (1984)

5 [14] Carraro, J., Prezzi, M., Salgado, R.: Shear strength and stiffness of sands containing plastic 6 and nonplastic fines. J. Geotech. and Geoenv. Eng., ASCE 135 (9), 1167-1178 (2009)

7 [15] Hattab, M., Fleureau, J.-M.: Experimental study of kaolin particle orientation mechanism.

8 Géotechnique 60 (5), 323 -332 (2010)

9 [16] Fonseca, J., O’ Sullivan, C., Coop, M. R., Lee, P. D.: Quantifying the evolution of soil 10 fabric during shearing using directional parameters. Géotechnique 63 (6), 487-499 (2013a)

11 [17] Fonseca, J., O’ Sullivan, C., Coop, M. R., Lee, P. D.: Quantifying the evolution of soil 12 fabric during shearing using scalar parameters. Géotechnique 63 (10), 818-829 (2013b)

13 [18] Nocilla, A., Coop, M. R., Colleselli, F.: The mechanics of an Italian silt; an example of 14 “transitional” behaviour. Géotechnique 56 (4), 261-271 (2006)

15 [19] Bruchon, J.-F., Pereira, J.-M., Vandamme, M., Lenoir, N., Delage, P., Bornert, M.: X-ray 16 microtomography characterisation of the changes in statistical homogeneity of an unsaturated 17 sand during imbibition. Géotechnique letters 3 (2), pp. 84-88 (2013)

18 [20] Todisco, M. C., Coop, M. R.: Quantifying rates of volumetric convergence in soils with 19 complex gradings. Submitted to Géotechnique (2016)

20 [21] Shipton, B., Coop, M. R.: On the compression behaviour of reconstituted soils. Soils and 21 Foundations $52(4), 668-681$ (2012)

[22] Takahashi, A., Jardine, R. J.: Assessment of standard research sand for laboratory testing. Quart. J. Eng. Geol. \& Hydrogeol. 40 (1), 93-103 (2007)

[23] Altuhafi, F. N., Coop, M. R.: Changes to particle characteristics associated with the compression of sands. Géotechnique 61 (6), 459-471 (2011)

26 [24] Ladd, R. S.: Preparing test specimens using undercompaction. Geot. Testing J ASTM, 14 27 (4), 371-382 (1978) 
1 [25] Atkinson, J. H., Evans, J. S.: Discussion on: The measurement of soil stiffness in the 2 triaxial apparatus, by Jardine, R. J., Symes, N. J. and Burland, J. B. Géotechnique 35 (3), 378$3382(1985)$

4 [26] Tatsuoka, F., Ishihara, M., Di Benedetto, H., Reiko, K.: Time-dependent shear 5 deformation characteristics of geomaterials and their simulation. Soils and Foundations 42 (2), $6 \quad 103-129(2002)$

7 [27] Li, P. Q. , Baudet, B. A.: Strain rate dependence of the critical state line of reconstituted 8 clays. Géotechnique letters 6 (1), 66-71 (2016)

9 [28] Bishop, A. W., Wesley, L. D.: A hydraulic triaxial apparatus for controlled stress path 10 testing. Géotechnique 25 (4), pp. 99-112 (1975)

11 [29] Pennington, D. S., Nash, D. F. T., Lings, M. L. Anisotropy of G0 shear stiffness in Gault 12 clay. Géotechnique 47 (3), 391-398 (1997)

13 [30] Todisco, M. C. Behaviour of non-convergent soils: effect of particle size, mineralogy and 14 fabric. PhD thesis, City University of Hong Kong, (2016)

15 [31] Abbiss, C. P.: Shear wave measurements of the elasticity of the ground. Géotechnique 31 16 (1), 91-104 (1981)

17 [32] Washburn, E. W.: The dynamics of capillary flow. Phys. Rev. L. 17 (3), 273-283 (1921)

18 [32] Klock, G. O., Boersma, L., DeBacker, L. W.: Pore size distributions as measured by the 19 mercury intrusion method and their use in predicting permeability. Soil Sci. Soc. Amer. Proc. $2033(1), 12-15(1969)$

21 [34] Diamond, S.: Pore size distribution in clays. Clays and Clay Minerals 18, 7-23 (1970)

22 [35] Penumadu, D., Dean, J.: Compressibility effect in evaluating the pore-size distribution of 23 kaolin clay using mercury intrusion porosimetry. Can. Geotech. J. 37 (2), 393-405 (2000)

24 [36] Folk, R. L., Ward, W. C.: Brazos River bar: a study in the significance of grain size 25 parameters. Journal of Sedimentary Petrology 27, 3-26 (1957)

26 [37] Pearson, K.: Editorial note to "Inequalities for moments of frequency functions and for 27 various statistical constants”. Biometrika 21 (1-4), 361-375 (1929) 
1 [38] Jaky, J.: Pressure in silos. Proc. 2nd ICSMFE, Rotterdam, Vol. 1, 103-107 (1948)

2 [39] Juang, C. H., Holtz, R. D.: Fabric, pore size distribution, and permeability of sandy soils.

3 J. Geotech. Engrg., ASCE, 112 (9), 855-868 (1986)

4 [40] Arson, C., Pereira, J.-M.: Influence of damage on pore size distribution and permeability 5 of rocks. International Journal for Numerical and Analytical Methods in Geomechanics 37(8), $6 \quad 810-831(2013)$

7 [41] Pereira, J.-M., Arson, C.: Retention and permeability properties of damaged porous rocks. 8 Computers and Geotechnics 48, 272-82 (2013)

\section{APPENDIX 1}

10 Micro X-ray CT imaging

11 Visually, the micro X-ray CT scan images in Fig. A1 of dense and loose oedometer samples of 12 LBS do not show significant differences in particle arrangement. The images also highlight a 13 key problem for the use of CT to characterise the fabric of these soils. At the scale shown of $14900 \mu \mathrm{m}$ across the image, there are insufficient larger particles and voids to be statistically reliable, and so much larger images would be needed. However, the sizes of the small particles and voids are already too small to be separated reliably by segmentation using existing methods within the resolution of the images, and this problem would be exacerbated for a larger image. For this reason, MIP testing was preferred. 


\section{TABLES}

2 Table 1 Details of oedometer tests on SPF and LMS

\begin{tabular}{|c|c|c|c|c|c|}
\hline Test & $\begin{array}{c}\text { Initial } \\
\text { void } \\
\text { ratio }\end{array}$ & $\begin{array}{c}\text { Void ratio at } \\
\text { maximum } \\
\sigma^{\prime}{ }_{\mathrm{v}}\end{array}$ & $\begin{array}{c}\text { Final void } \\
\text { ratio }\end{array}$ & $\begin{array}{c}\text { Vertical } \\
\text { stress, } \sigma^{\prime}{ }_{\mathrm{v}} \\
{[\mathrm{kPa}]}\end{array}$ & $\begin{array}{c}\mathrm{p}^{\prime} \\
{[\mathrm{kPa}]^{* *}}\end{array}$ \\
\hline LI & 0.893 & 0.501 & 0.501 & 56 & $37\left(\mathrm{k}_{0}=0.49\right)$ \\
\hline DI & 0.429 & 0.371 & 0.371 & 56 & $37\left(\mathrm{k}_{0}=0.49\right)$ \\
\hline LF & 1.068 & 0.306 & 0.357 & 7700 & $5000\left(\mathrm{k}_{0}=0.49\right)$ \\
\hline DF & 0.443 & 0.263 & 0.306 & 7700 & $5000\left(\mathrm{k}_{0}=0.49\right)$ \\
\hline Loose-kaolin & 2.050 & 0.512 & 0.788 & 7700 & - \\
\hline Dense-kaolin & 1.804 & 0.512 & 0.747 & 7700 & - \\
\hline LMS-OED1* & $\mathbf{0 . 5 6 9}$ & $\mathbf{0 . 2 4 6}$ & $\mathbf{0 . 2 5 6}$ & $\mathbf{4 8 0 0 0}$ & $\mathbf{2 8 0 0 0}\left(\mathbf{k}_{0}=\mathbf{0 . 3 8}\right)$ \\
\hline LMS-OED2* & $\mathbf{0 . 4 2 0}$ & $\mathbf{0 . 1 5 2}$ & $\mathbf{0 . 1 9 6}$ & $\mathbf{4 8 0 0 0}$ & $\mathbf{2 8 0 0 0}\left(\mathbf{k}_{\mathbf{0}}=\mathbf{0 . 3 8}\right)$ \\
\hline
\end{tabular}

*selected samples for MIP tests, ${ }^{* *} \mathrm{k}_{0}$ values calculated from Jaky's relation $\left(\mathrm{k}_{0}=1-\sin \varphi{ }^{\prime}\right)$

4 Table 2 Details of triaxial tests on SPF, LBS and LMS

\begin{tabular}{|c|c|c|c|c|c|c|c|}
\hline Test & $\begin{array}{c}\text { Initial } \\
\text { void } \\
\text { ratio }\end{array}$ & $\begin{array}{c}\text { Void ratio } \\
\text { end of iso- } \\
\text { compression }\end{array}$ & $\begin{array}{c}\text { Void } \\
\text { ratio } \\
\text { end of } \\
\text { shearing }\end{array}$ & $\begin{array}{c}\mathbf{p} \text { end of } \\
\text { iso- } \\
\text { compression } \\
{[\mathbf{k P a}]}\end{array}$ & $\begin{array}{c}\text { p' end of } \\
\text { shearing } \\
{[\mathrm{kPa}]}\end{array}$ & $\begin{array}{c}\text { Volumetric } \\
\text { strain } \\
{[\%]}\end{array}$ & $\begin{array}{c}\text { Shear } \\
\text { strain } \\
{[\%]}\end{array}$ \\
\hline SPF1 & 0.593 & 0.513 & 0.454 & 300 & 500 & 8.9 & 20 \\
\hline SPF2 & 0.407 & 0.368 & 0.382 & 300 & 500 & 1.7 & 32 \\
\hline LBS1 & 0.544 & 0.476 & 0.460 & 1000 & 1700 & 7.2 & 20 \\
\hline LBS2* & $\mathbf{0 . 4 3 7}$ & $\mathbf{0 . 3 9 7}$ & $\mathbf{0 . 3 8 8}$ & $\mathbf{5 0 0}$ & $\mathbf{8 4 0}$ & $\mathbf{3 . 4}$ & $\mathbf{3 0}$ \\
\hline LBS9* & $\mathbf{0 . 5 5 1}$ & $\mathbf{0 . 4 9 0}$ & $\mathbf{0 . 4 6 6}$ & $\mathbf{5 0 0}$ & $\mathbf{9 5 0}$ & $\mathbf{5 . 5}$ & $\mathbf{2 3}$ \\
\hline LBS10 & 0.436 & 0.319 & 0.281 & 5300 & 9700 & 8.6 & 17 \\
\hline LBS14 & 0.435 & 0.405 & 0.422 & 100 & 190 & 0.9 & 21 \\
\hline LBS16* & $\mathbf{0 . 5 8 3}$ & $\mathbf{0 . 5 1 1}$ & $\mathbf{0 . 4 7 2}$ & $\mathbf{5 0 0}$ & $\mathbf{9 2 0}$ & $\mathbf{7 . 1}$ & $\mathbf{9}$ \\
\hline LBS17* & $\mathbf{0 . 4 5 7}$ & $\mathbf{0 . 4 0 9}$ & $\mathbf{0 . 3 8 6}$ & $\mathbf{5 0 0}$ & $\mathbf{1 0 0 0}$ & $\mathbf{4 . 9}$ & $\mathbf{5}$ \\
\hline LMS15 & 0.415 & 0.332 & 0.288 & 2400 & 5100 & 9.1 & 27 \\
\hline
\end{tabular}




\begin{tabular}{|c|c|c|c|c|c|c|c|}
\hline LMS17 & 0.373 & 0.286 & 0.234 & 3900 & 7900 & 10.4 & 27 \\
\hline LMS21 & 0.492 & 0.408 & 0.389 & 500 & 524 & 7.0 & 22 \\
\hline
\end{tabular}


1 Table 3 Statistical parameters of SPF and comparable data of LBS and LMS.

\begin{tabular}{|c|c|c|c|c|c|c|c|c|}
\hline Test & $\begin{array}{l}\text { Mean, } \\
\mu[\mu \mathrm{m}]\end{array}$ & $\begin{array}{c}\text { Median, } \\
\text { m } \\
{[\mu \mathrm{m}]}\end{array}$ & $\begin{array}{c}\text { Standard } \\
\text { deviation, } \\
\sigma[\mu \mathrm{m}]\end{array}$ & $\begin{array}{c}\text { Skewness, } \\
\gamma\end{array}$ & $\begin{array}{l}\text { Kurtosis, } \\
\kappa\end{array}$ & $d_{60} / d_{10}$ & $\begin{array}{c}\begin{array}{c}\text { Diameter } \\
\text { at } \\
\text { highest }\end{array} \\
\text { Peak } \\
{[\mu \mathrm{m}]}\end{array}$ & $\begin{array}{c}\text { Diameter } \\
\text { at } \\
\text { smallest } \\
\text { Peak } \\
{[\mu \mathrm{m}]}\end{array}$ \\
\hline $\begin{array}{c}\text { SPF- } \\
\text { OED-LI }\end{array}$ & 0.76 & 0.71 & 5.77 & 0.63 & 4.42 & 10.36 & 1.60 & 0.58 \\
\hline $\begin{array}{c}\text { SPF- } \\
\text { OED-DI }\end{array}$ & 0.54 & 0.46 & 5.81 & 0.96 & 5.24 & 7.42 & 0.37 & 0.91 \\
\hline $\begin{array}{l}\text { SPF- } \\
\text { OED- } \\
\text { LF }\end{array}$ & 0.57 & 0.47 & 6.18 & 0.97 & 4.90 & 7.40 & 0.42 & 1.02 \\
\hline $\begin{array}{l}\text { SPF- } \\
\text { OED- } \\
\text { DF }\end{array}$ & 0.39 & 0.29 & 5.73 & 1.32 & 6.05 & 5.30 & 0.27 & 1.42 \\
\hline SPF1 & 1.15 & 0.52 & 11.89 & 0.77 & 2.62 & 8.30 & - & - \\
\hline SPF2 & 0.68 & 0.46 & 7.85 & 1.05 & 4.37 & 7.40 & - & - \\
\hline LBS2 & 1.85 & 1.89 & 4.49 & 0.78 & 5.86 & 6.01 & - & - \\
\hline LBS9 & 1.84 & 1.98 & 3.78 & 0.88 & 6.35 & 6.75 & - & - \\
\hline LBS16 & 1.84 & 1.79 & 4.12 & 0.81 & 5.99 & 5.35 & - & - \\
\hline LBS17 & 1.79 & 1.63 & 4.12 & 1.22 & 6.59 & 4.79 & - & - \\
\hline $\begin{array}{l}\text { LMS- } \\
\text { OED1 }\end{array}$ & 2.71 & 1.76 & 4.78 & 1.88 & 4.21 & 3.07 & - & - \\
\hline $\begin{array}{l}\text { LMS- } \\
\text { OED2 }\end{array}$ & 2.57 & 1.45 & 5.37 & 1.54 & 3.29 & 3.03 & - & - \\
\hline
\end{tabular}


1 FIGURES

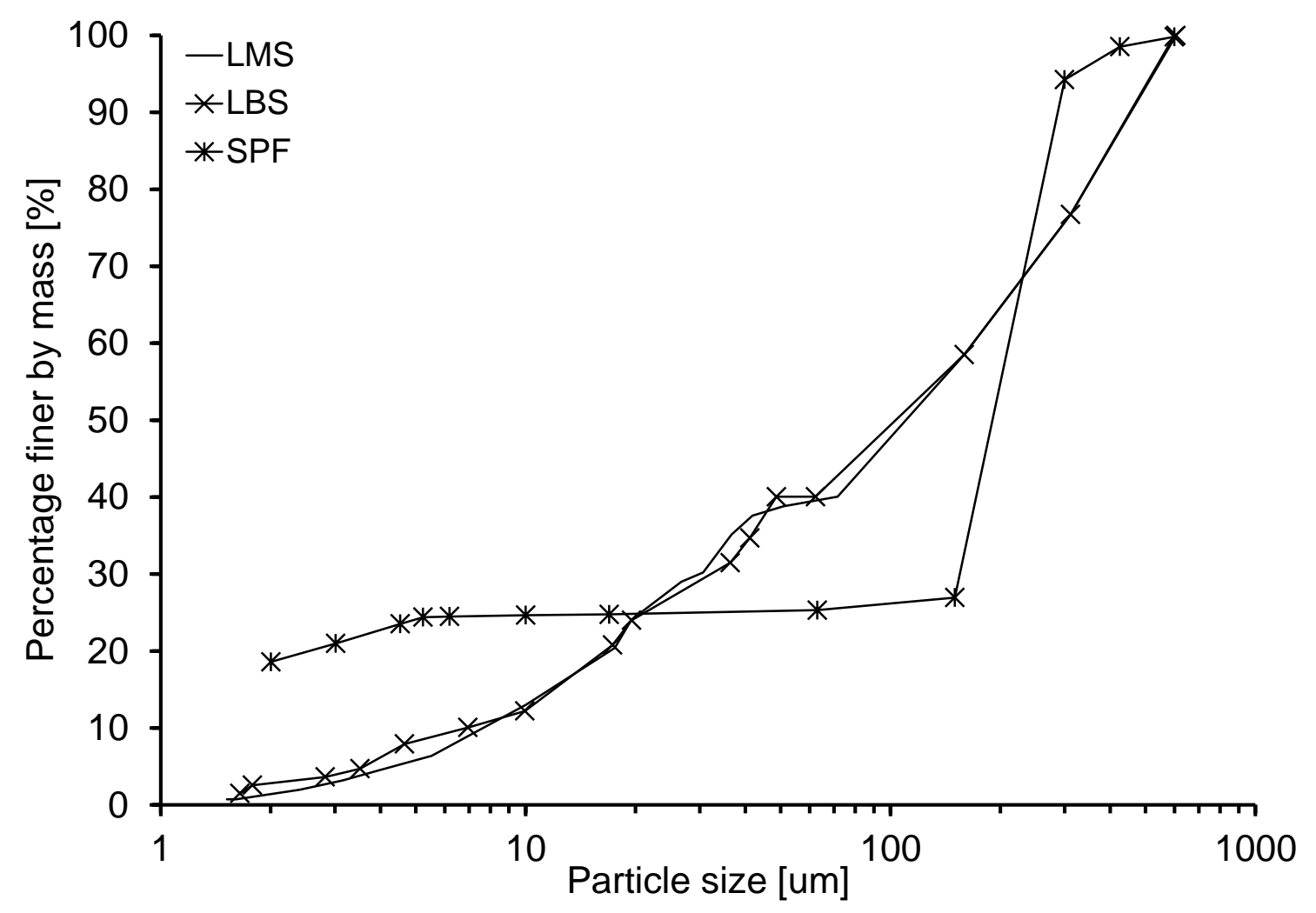

3 Figure 1 Grain size distributions of the tested mixtures

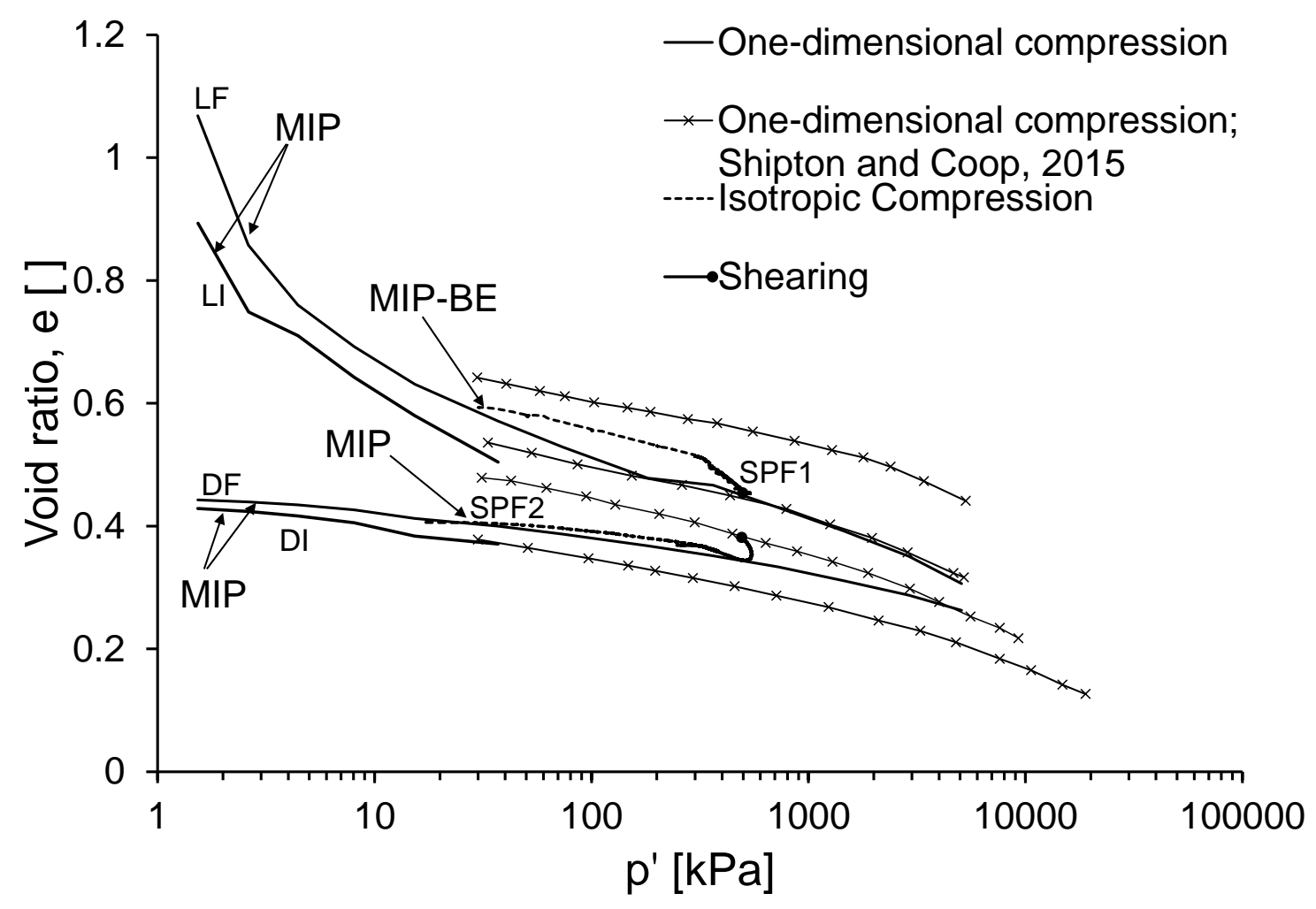

5 a) 


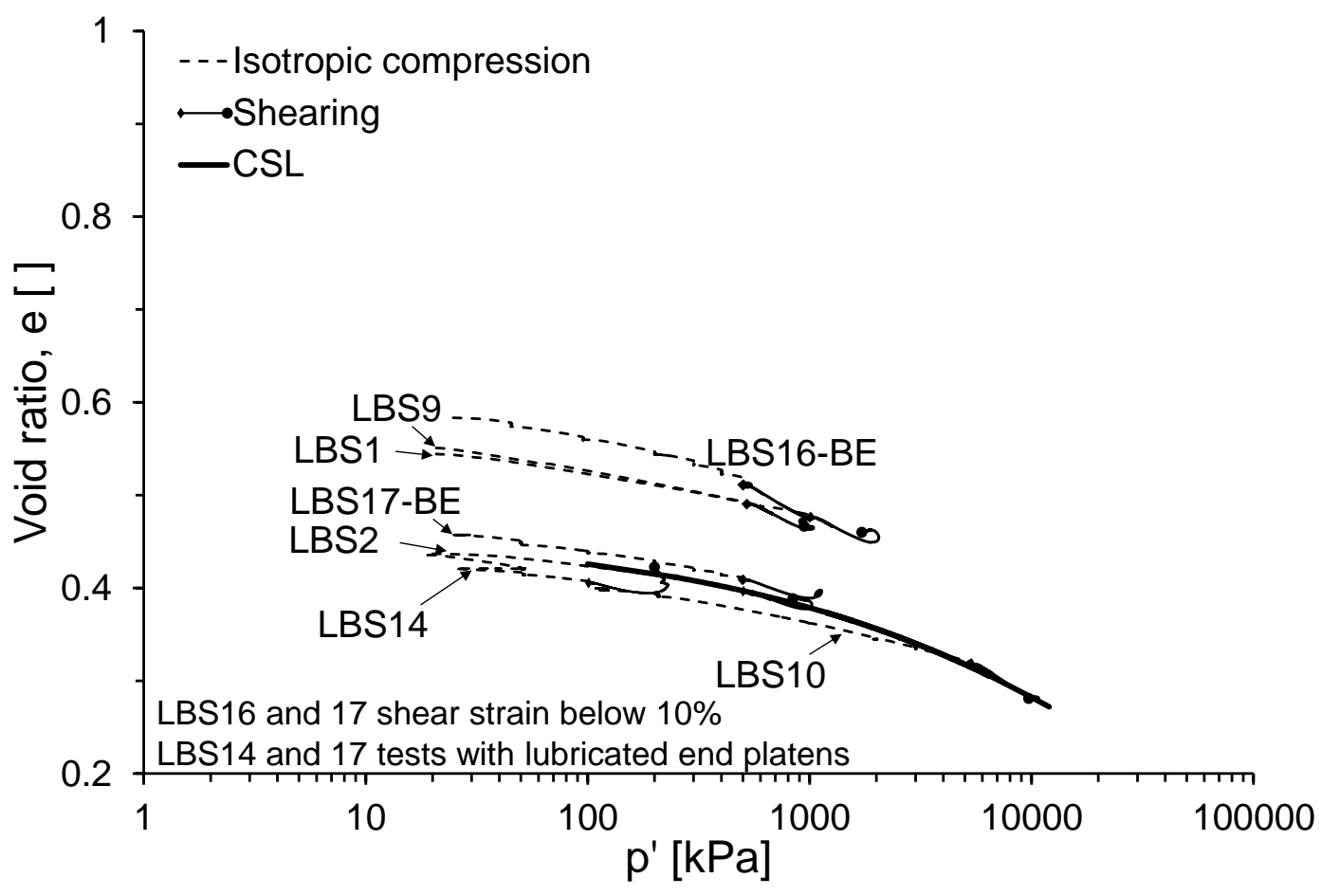

2 b)

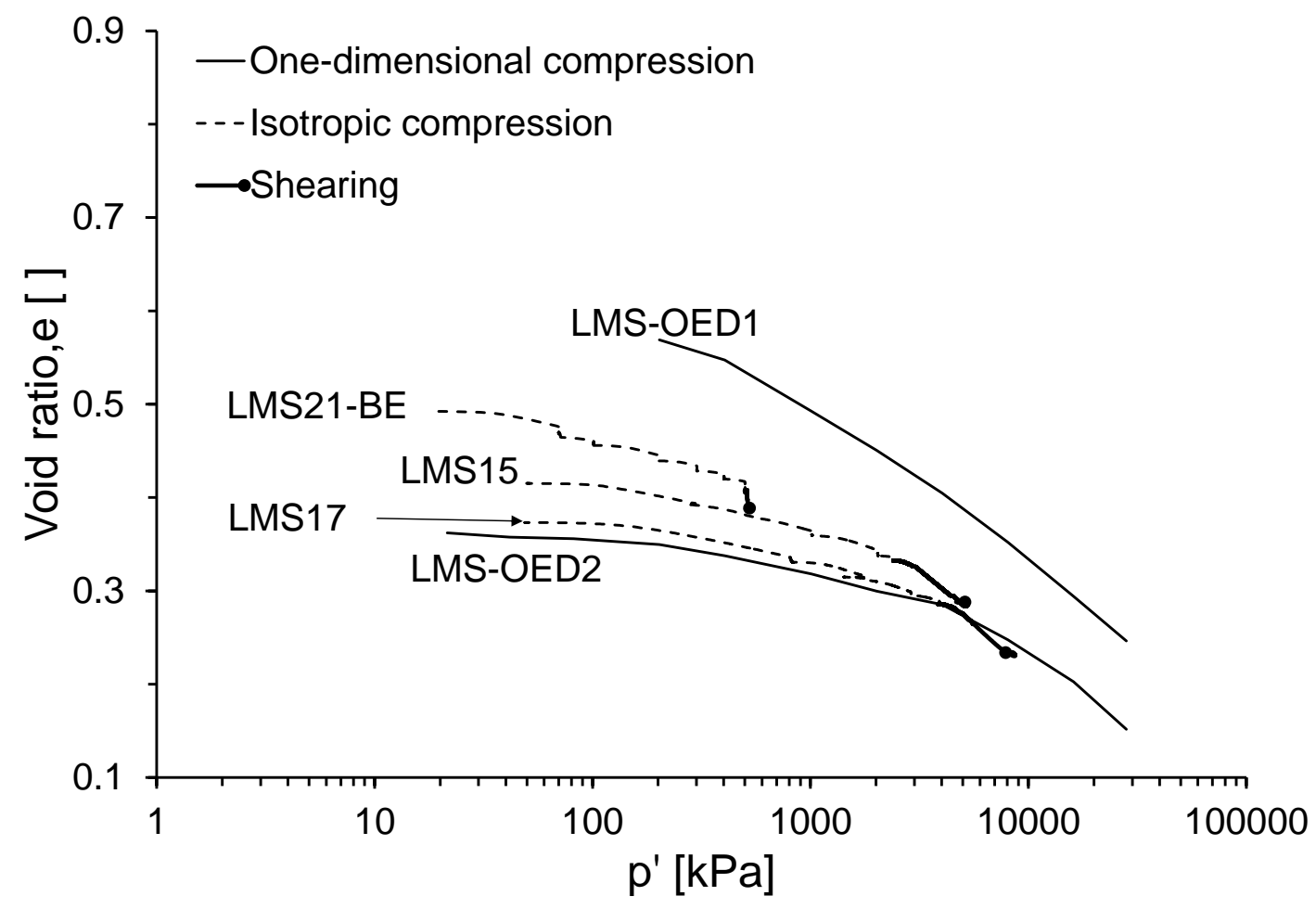

$4 \quad c)$

5 Figure 2 MIP and Bender element testing on oedometer and triaxial samples of a) SPF, b)LBS 6 and c) LMS samples 


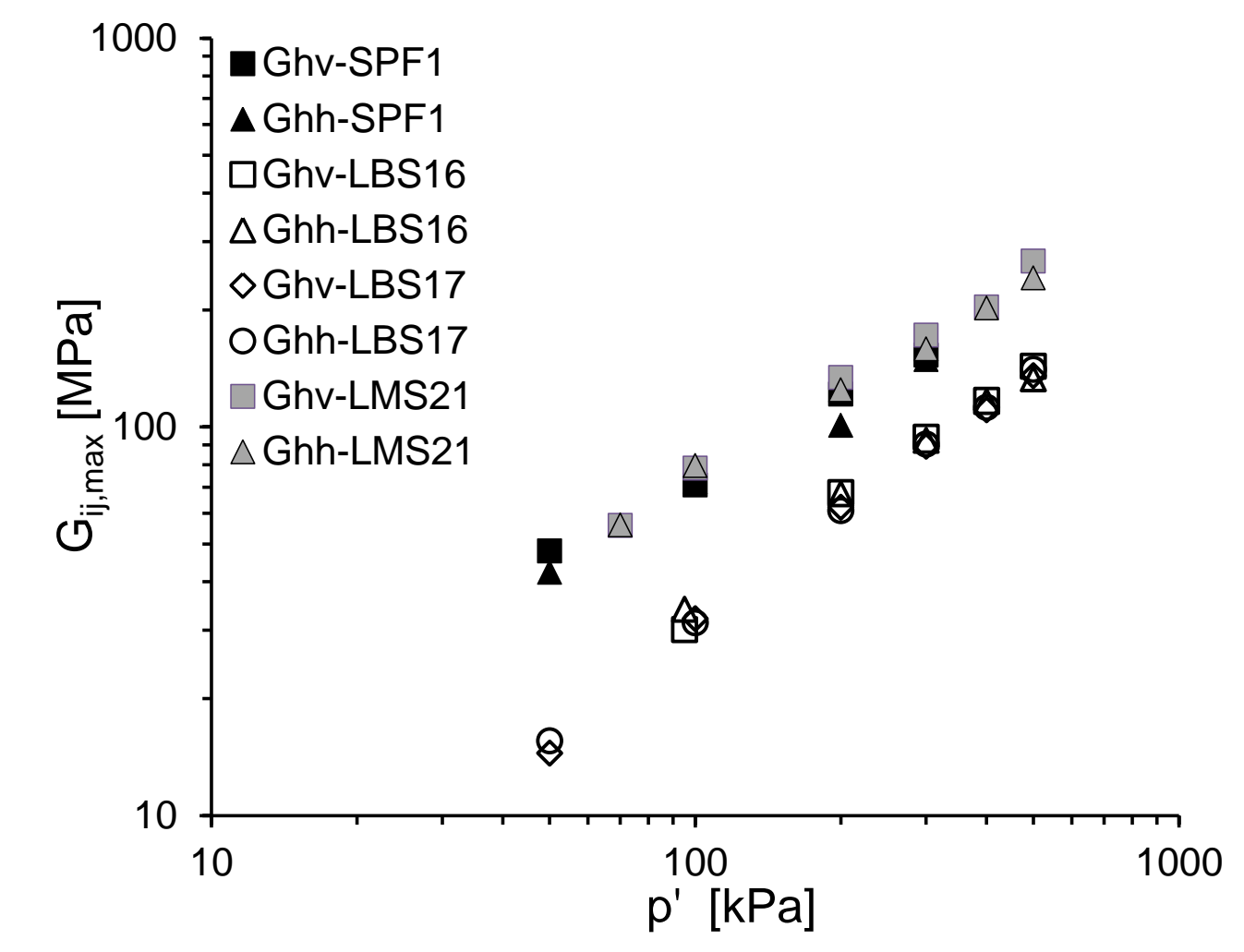

2 Figure 3 Elastic shear moduli of the tested mixtures obtained by bender element testing during 3 isotropic compression. 


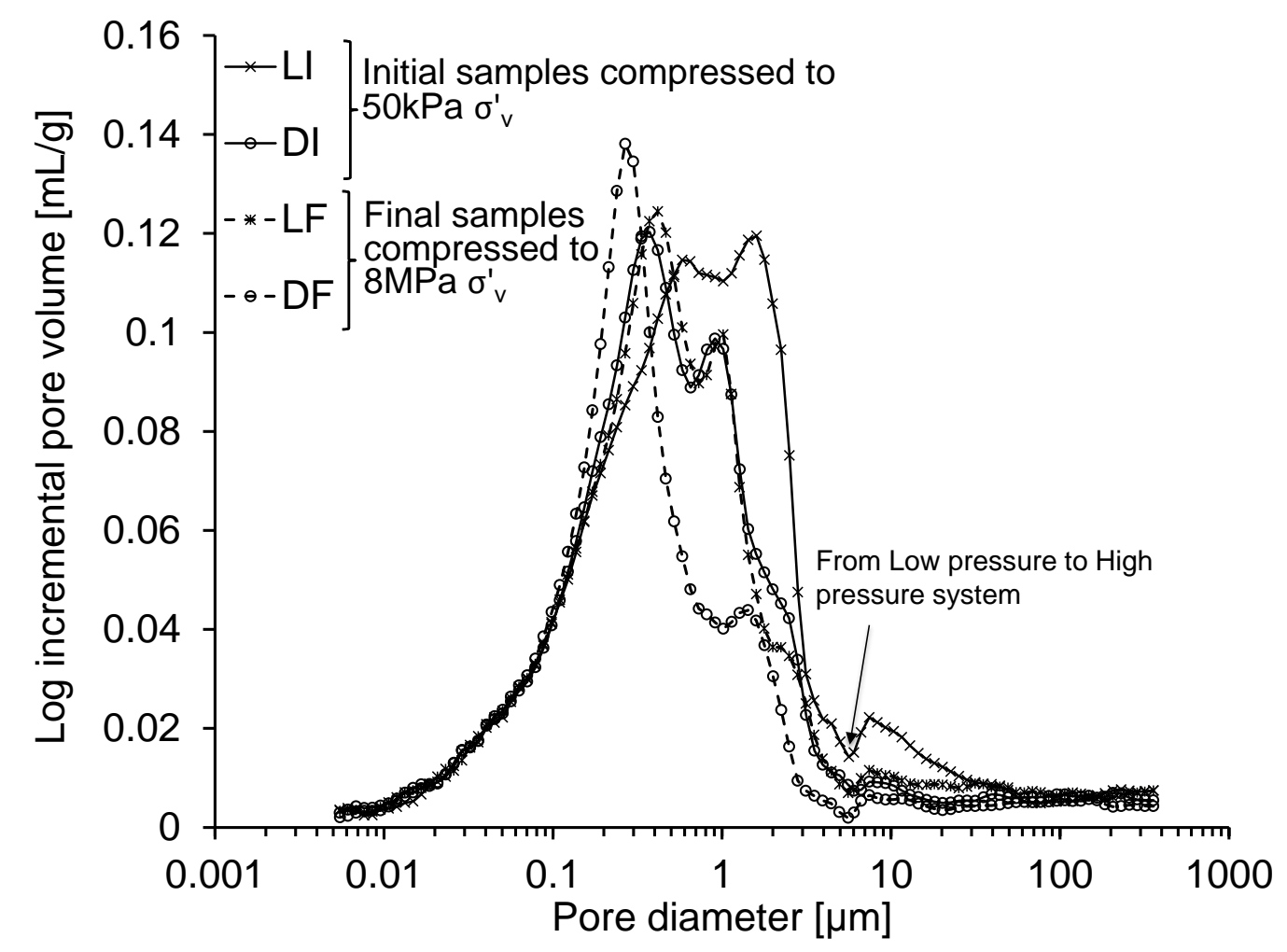

2 a)

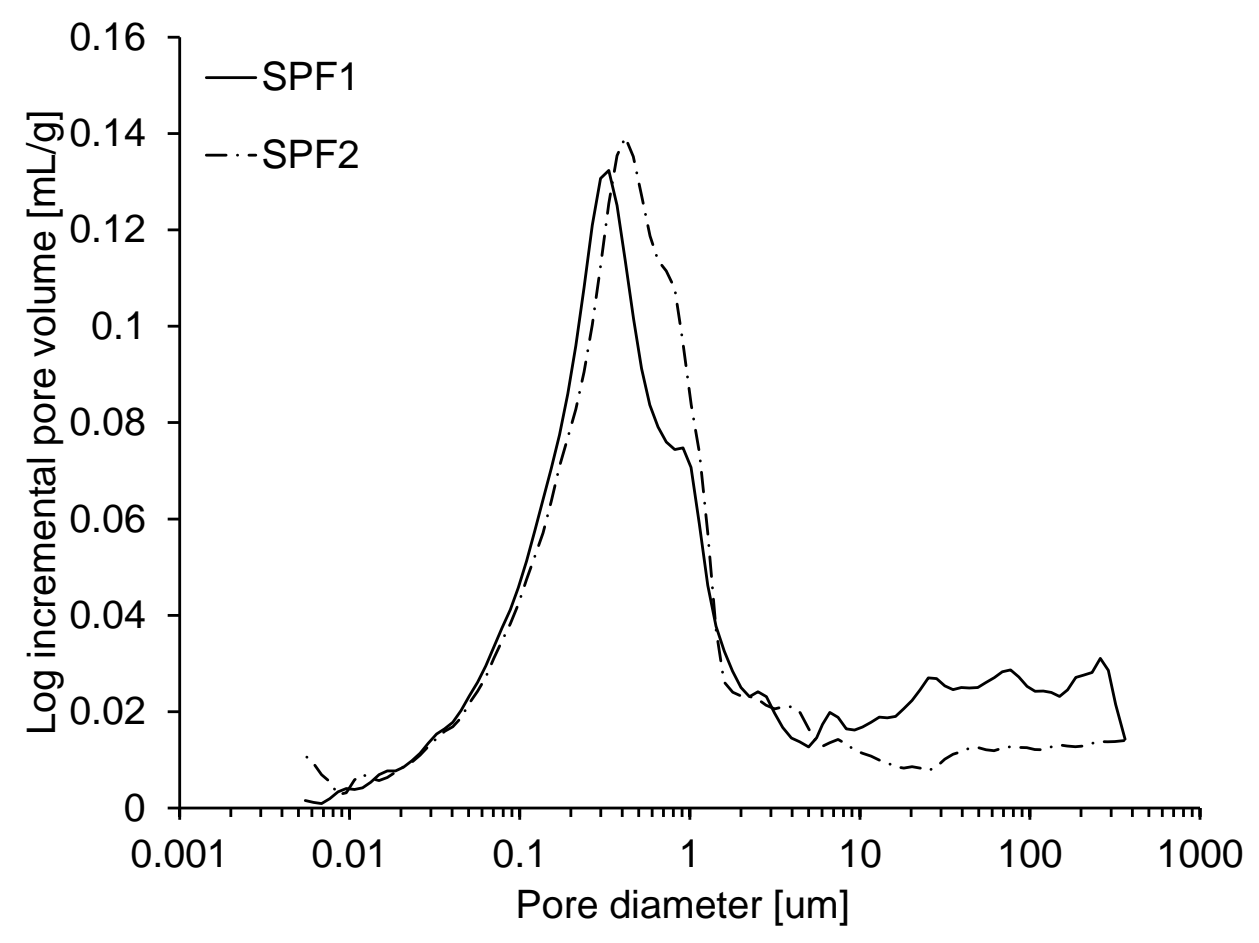

4 b)

5 Figure 4 Density functions of the intruded volume of mercury of a) oedometer and b) triaxial 6 samples of SPF. 


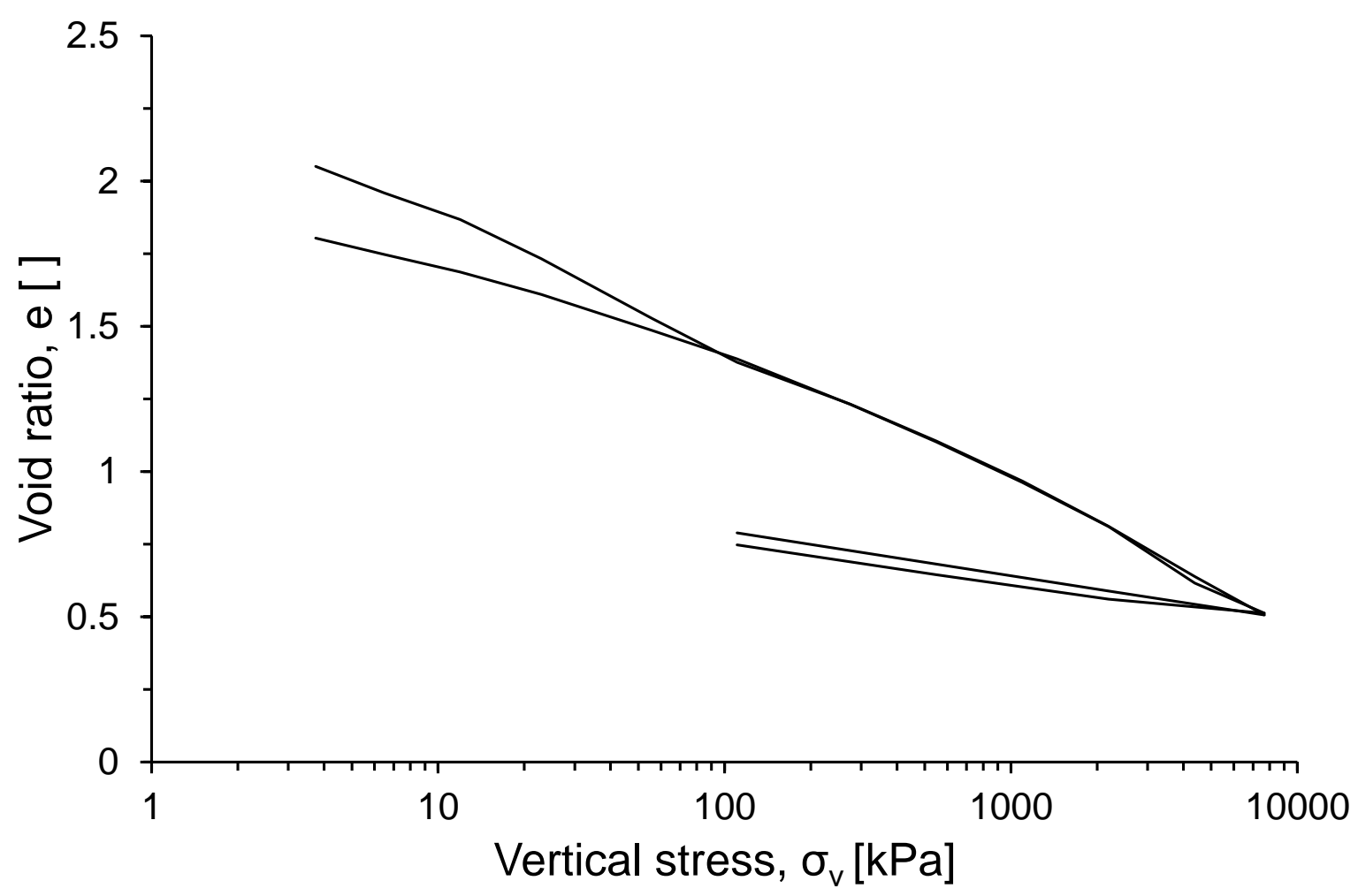

a)

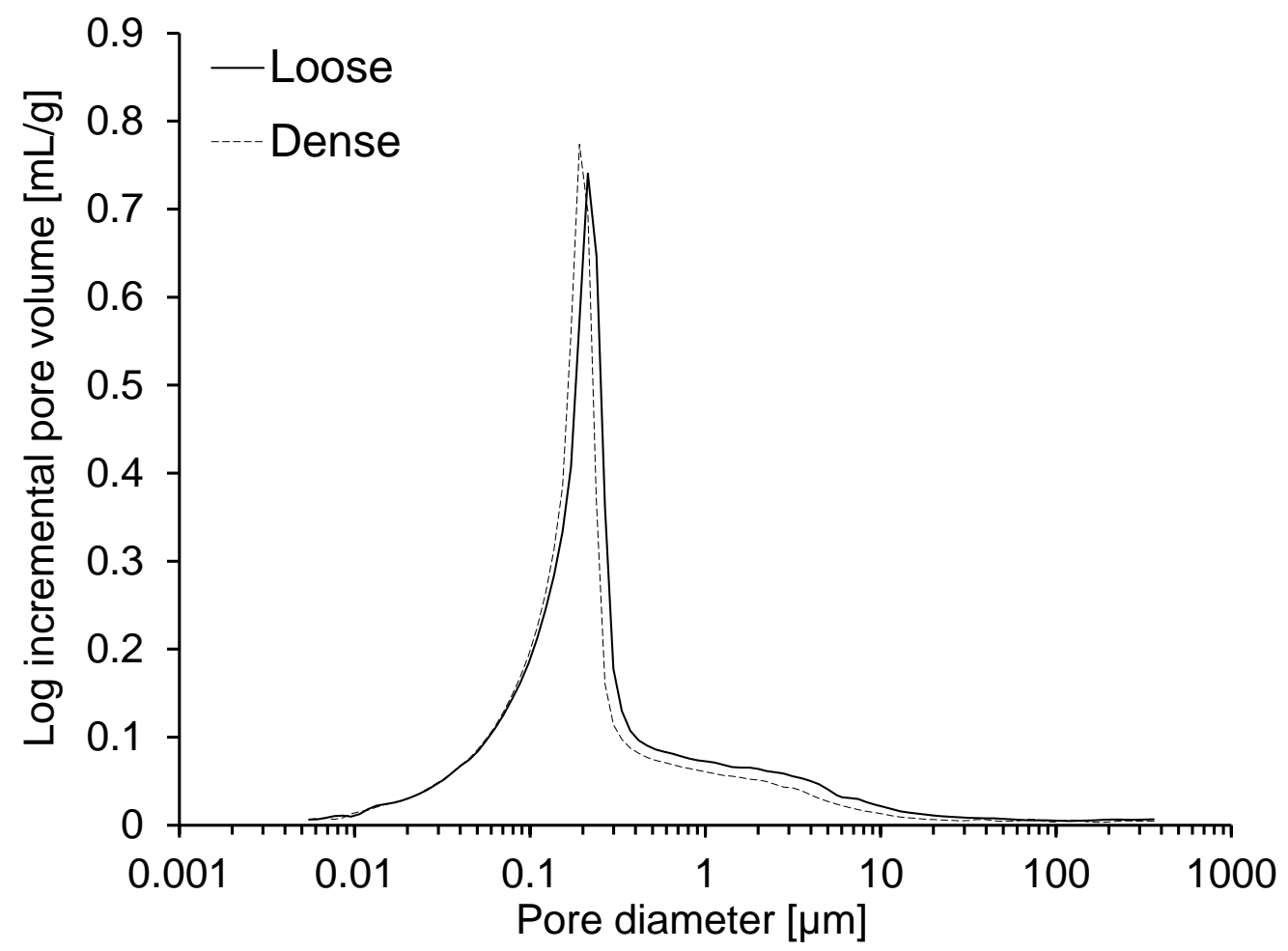

3

4 b)

5 Figure 5 Oedometer tests on kaolin samples: a) compression data, b) MIP tests. 


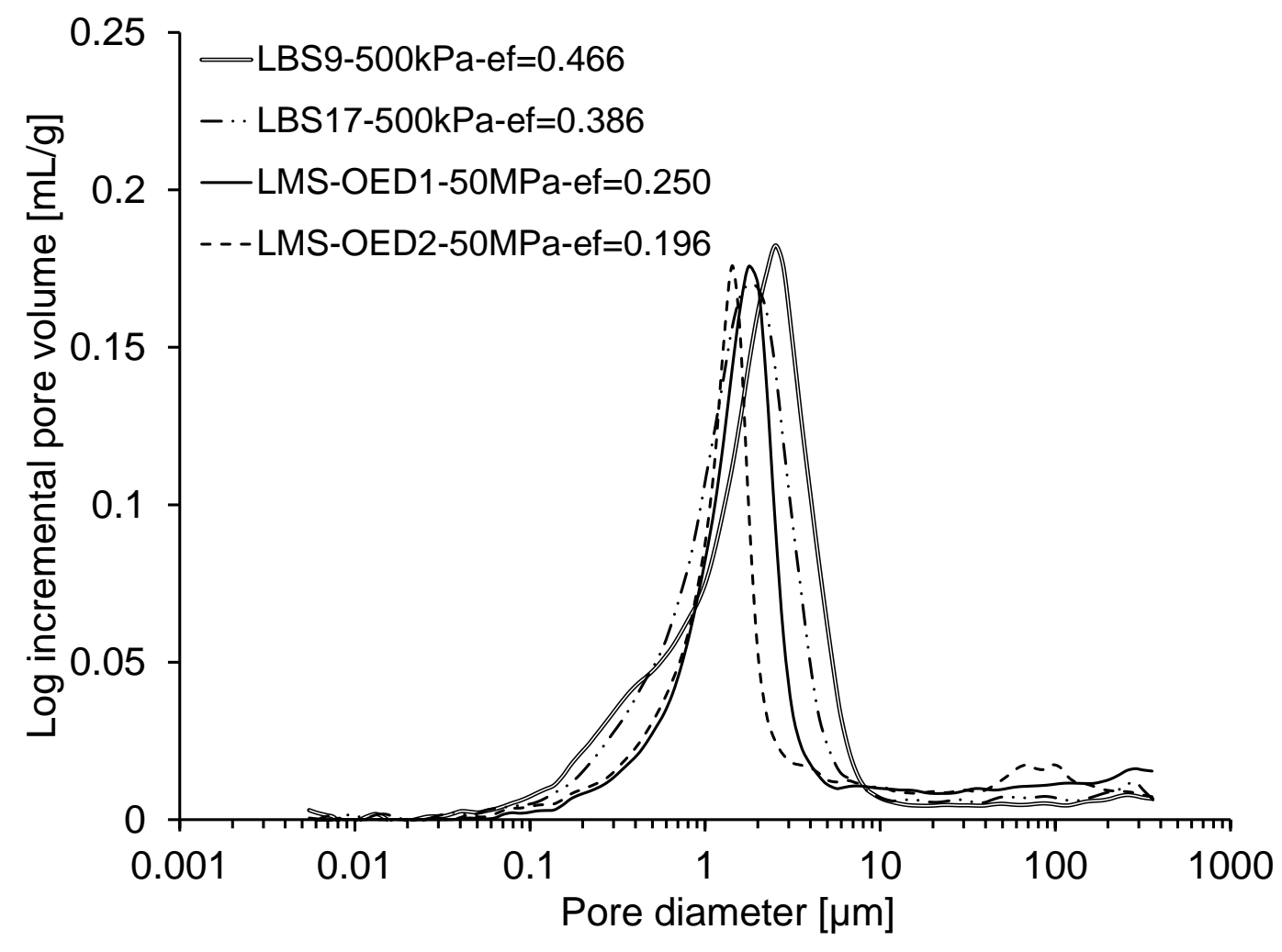

2 Figure 6 Density functions of the intruded volume of mercury of oedometer samples of LMS 3 and selected triaxial samples of LBS. 


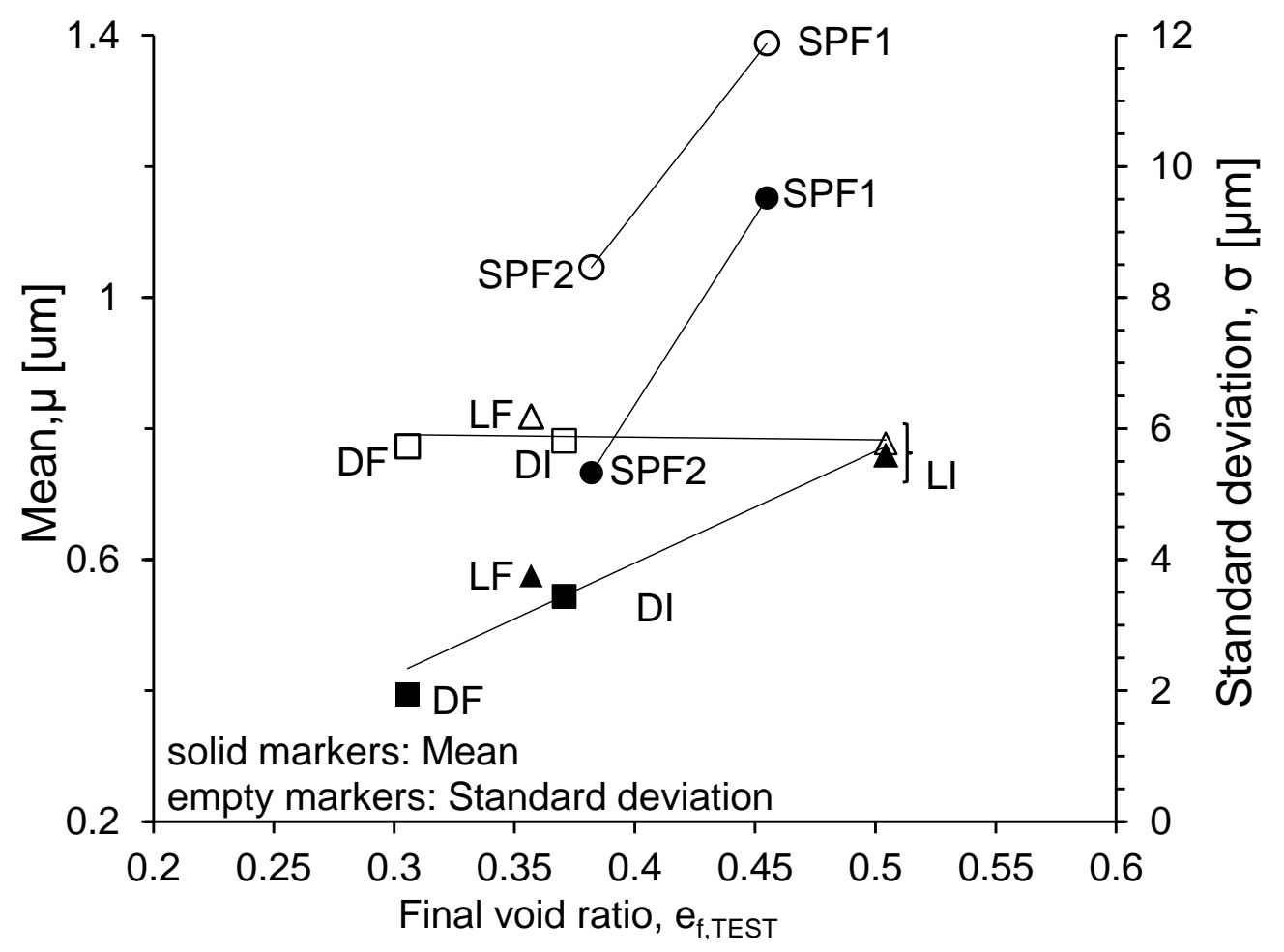

2 a)

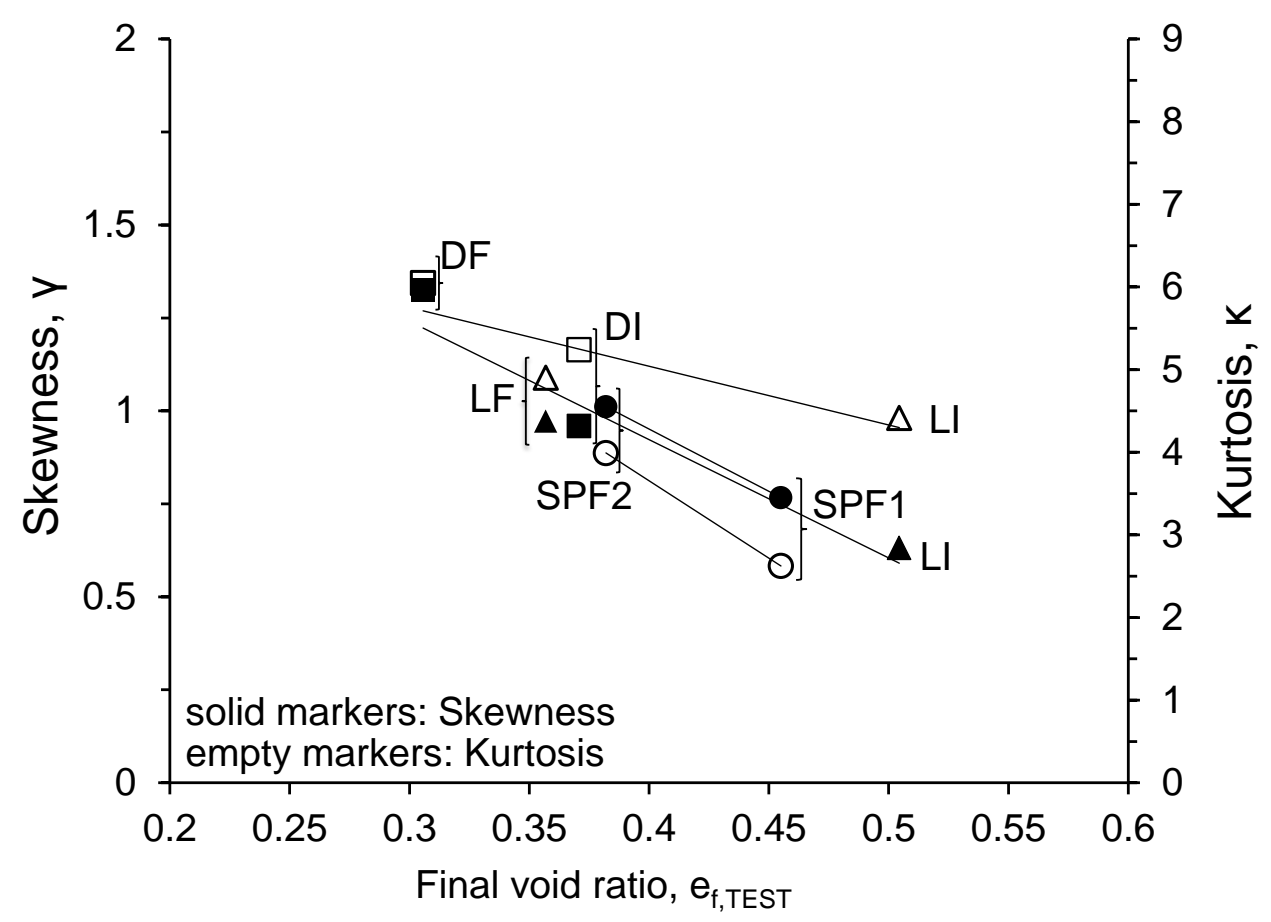

4 b)

5 Figure 7 Statistical parameters of the PSDs of SPF: a) mean and standard deviation, b) 6 skewness and kurtosis. 


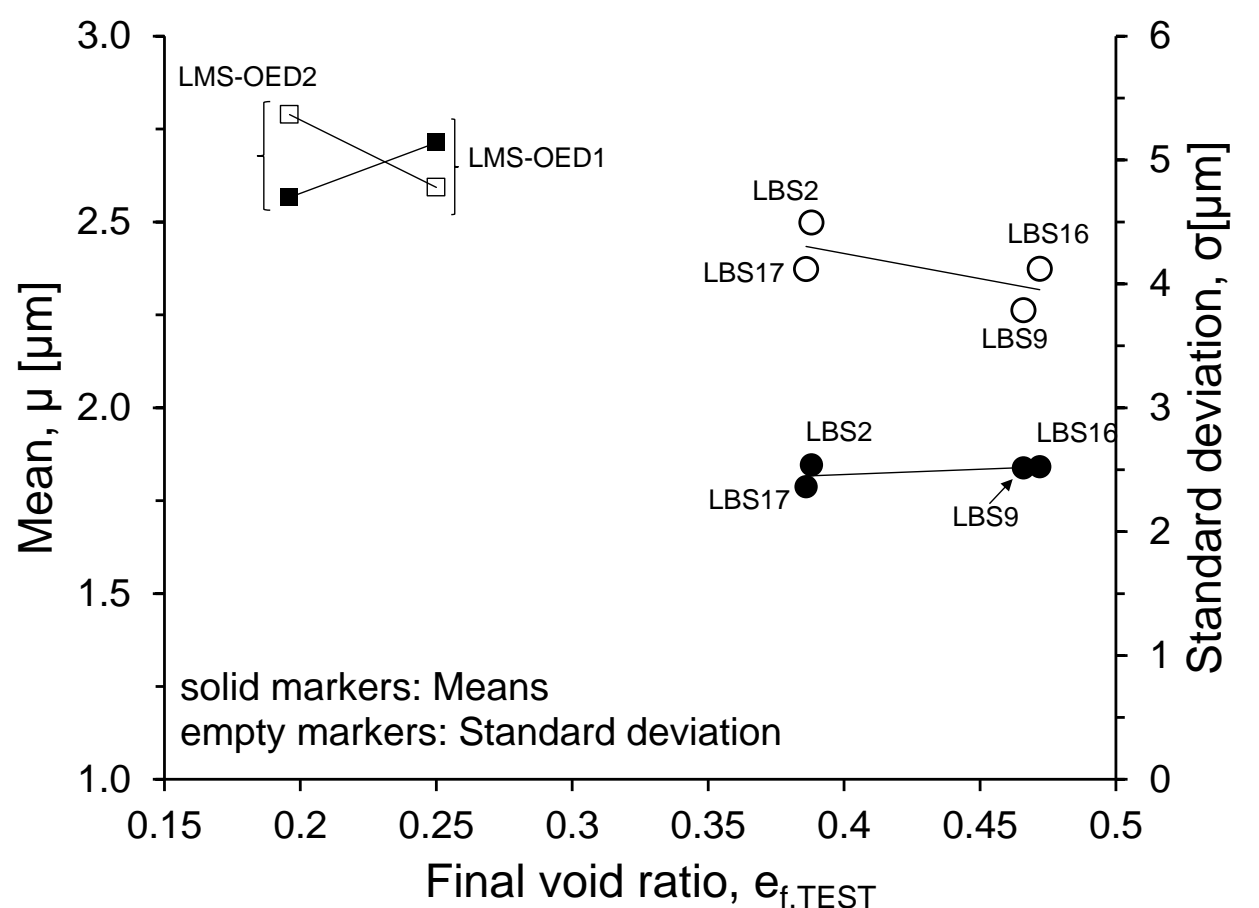

1

2 a)

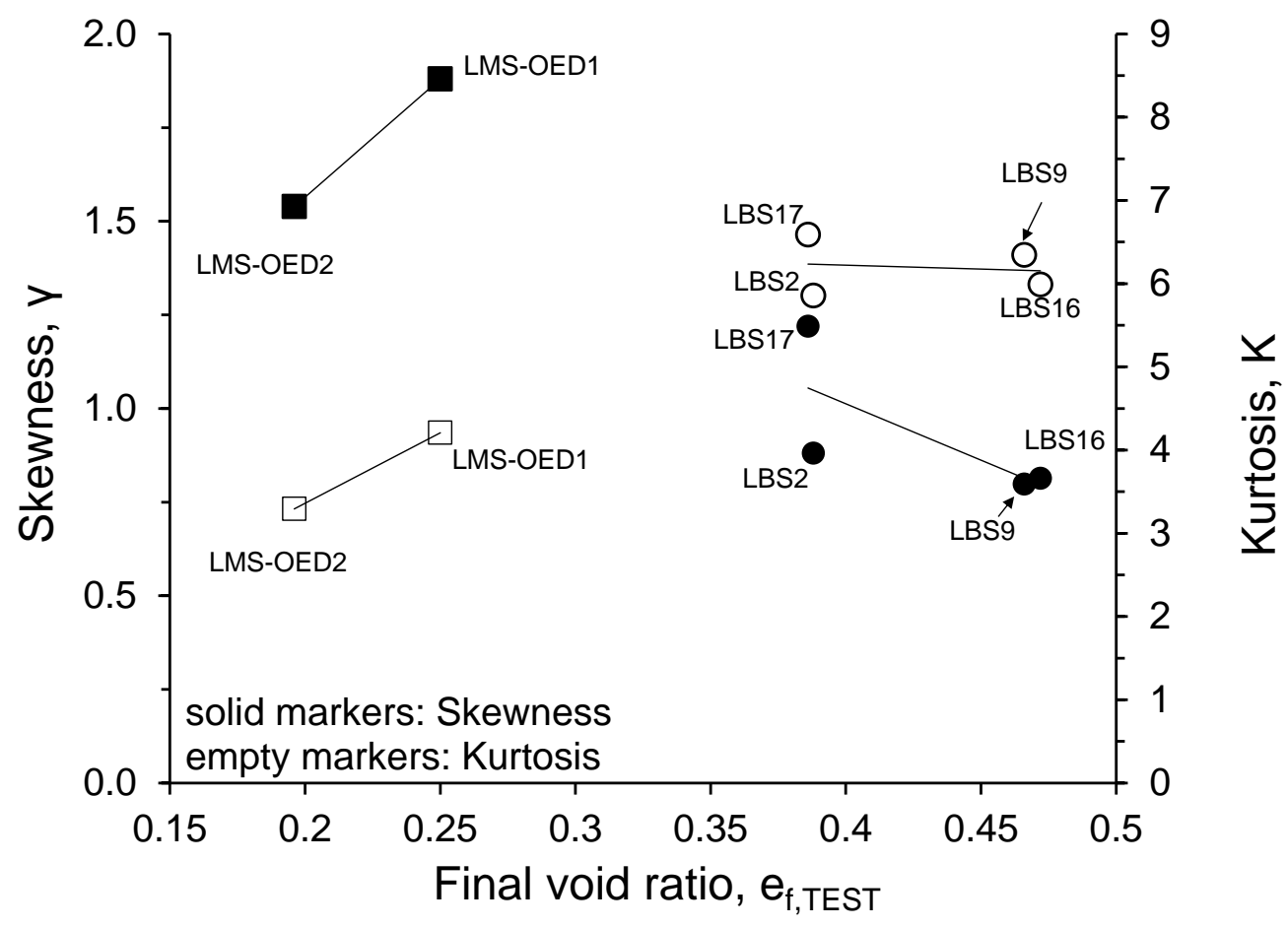

4 b)

5 Figure 8 Statistical parameters of the PSDs of LBS and LMS: a) mean and standard deviation, 6 b) skewness and kurtosis. 


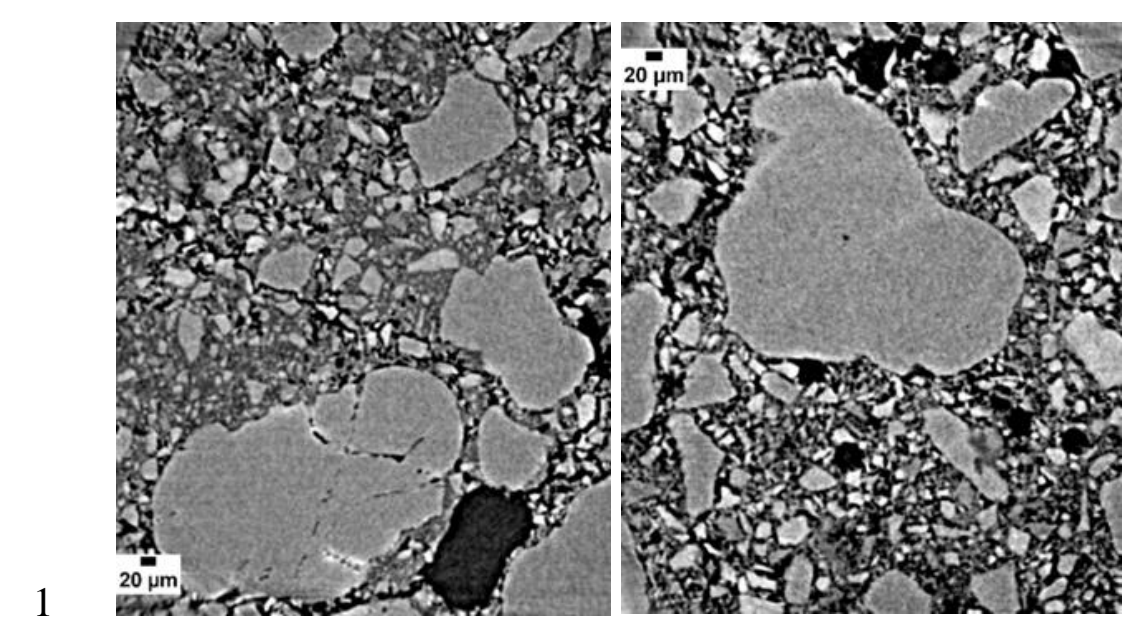

2 Figure A1 CT scan images of oedometer tests on LBS compressed to 50kPa: a) loose and b) 3 dense (beam energy $21 \mathrm{keV}$, average voxel resolution $0.625 \mu \mathrm{m}$ ).

4 